\title{
Escrito para a cena barroca: a contextualização histórica na leitura contemporânea de textos dramáticos antigos
}

\author{
Carlos Gontijo Rosa*
}

Falamos que o leitor, a partir do seu próprio imaginário, constrói as cenas que lê num texto dramático. Assim, num contato mais imediato com o texto, o leitor organiza as ações da peça a partir de seu próprio referencial imagético. Em textos contemporâneos, especialmente aqueles que dialogam diretamente com as novas formas da cena, com sua hibridização entre as diferentes formas artísticas, é evocada a necessidade de algum conhecimento desta cena, pois o texto dramático é escrito, como já dito, com vistas a ser posto em cena em sua contemporaneidade. O mesmo acontece com o texto dramático antigo, pois também ele dialoga com as formas de representação vigentes. Tal relação é especialmente importante de ser levada em conta quando se está em contato com textos definitivamente escritos com o objetivo de serem representados, como o corpus deste trabalho. Entretanto, a condição de serem escritos para a cena não exime o autor de tais textos de um compromisso literário, mas agrega ambos sob sua égide.

Portanto, quando nós, leitores do século XXI, nos deparamos com os textos dramáticos em geral, apresentamos uma tendência a lê-los primeiramente a partir do nosso imaginário do que é teatro hoje. Sabemos que nossa imaginação está impregnada do nosso próprio tempo-espaço e apresenta as mais diversas influências, inconscientemente. Assim, porque "a leitura de um texto dramatúrgico implica inicialmente um intenso envolvimento com o universo que se oferece a nossa imaginação" (KopelmAN, 2011, p. 62), o leitor naturalmente aloca a narrativa dramática, imageticamente, em seu próprio contexto. Reciprocamente, a própria matéria da leitura também interfere sobre o contexto do leitor, que já não será mais o mesmo de antes do contato com o texto. Entretanto, por mais que o leitor contemporâneo não tenha afinidade ou conhecimento das mais recentes estéticas teatrais, ainda assim, quando se trata de um texto setecentista, suas referências estarão séculos à frente dos modelos de representação barrocos. Para não nos alongarmos neste assunto tangente à pesquisa, basta lembrarmos que o modo de interpretação realista, especialmente o método desenvolvido por Constantin Stanislavski, revoluciona as artes cênicas no século XX e torna-se o ponto principal de referência de re-

\footnotetext{
Doutor em Literatura Portuguesa (2017) e atualmente pós-doutorando em Literatura Brasileira
} na Universidade de São Paulo. E-mail: carlosgontijo@gmail.com. 
presentação teatral, quer através do próprio teatro, quer de sua apropriação para o cinema e TV.

Não nos interessa desprestigiar este caminho de leitura dramática, o qual consideramos válido para uma livre apreciação dos textos dramáticos. Esta leitura, inclusive, apresenta pontos positivos, pois aproxima o leitor e faz com que ele se relacione mais intimamente com os textos lidos. Como fala Ruiz Ramón (1987, p. 36) acerca das relações entre espaço dramático e espaço histórico:

De todos es el más complejo, pues, querámoslo o no, tenemos que pensarlo desde nuestro propio espacio histórico. El riesgo que la objetividad corre es enorme, máxime si reconocemos que también la objetividad es histórica.

Ao estabelecer paralelos entre os textos antigos e a sua realidade contemporânea, o leitor pode, a partir de uma ressignificação do material literário, apreciálo e compreendê-lo, ou seja, ele pode fruir o texto através deste contato. Assim, por exemplo, atribuímos tanto valor a uma boa leitura de Antígona como o fazem Brecht ou Anouilh, que enxergam em Antígona uma protagonista revolucionária avant-garde, quanto a uma leitura aristotélica, que enxerga as forças da pólis e da génos como antinômicas e autoexcludentes, tendo Créonte como o protagonista que comete a falha trágica.

Entretanto, no que tange ao tratamento de textos muito antigos ou baseados em preceptivas muito distantes das conhecidas pelo leitor, esta relação assimétrica pode prejudicar a apreciação da obra:

Tendemos a construir nossa ideia de representação teatral a partir da experiência contemporânea que temos dela; tal construção, que há sempre de ser limitada, pode às vezes ser ineficaz ao nos fazer abordar uma arte variada e contínua como se fosse um hábito singular e fixo. (Williams, 2010, p. 36)

Uma leitura empenhada de textos, dramáticos ou não, deve considerar seu contexto de produção, seja histórico-cultural, seja cênico-literário. Esta condição da leitura permitirá que o leitor compreenda os meandros do jogo cênico proposto pelo dramaturgo e complementará o caráter imaginativo do ato de ler. ${ }^{1}$

Em última instância, "trata-se aqui do particular dentro do universal; alguma coisa que, referida à experiência, às crenças, diríamos modernamente, à cultura de um povo, encontre nele ressonância. Provavelmente, A Dama das Camélias, de Alexandre Dumas Filho, apresentada a indígenas brasileiros, não lhes faria nenhum efeito, ainda que devidamente traduzida. O conhecimento do ambiente parisiense do século passado, dos preconceitos ali vigentes, dos interesses do dinheiro e dos costumes, em oposição ao amor romântico, é fundamental para a fruição (até para a rejeição) desse tipo de drama” (Pallottini, 2015, p. 44) 
Deve-se observar, contudo, que não são proposições de leitura contraditórias. Uma vez que não podemos nos distanciar integralmente de nosso próprio momento histórico, que esta condição concorra no sentido de privilegiar a leitura. $\mathrm{O}$ equilíbrio, porém, não é cartesianamente delimitado e deve estar subordinado às condições do ato de ler, ou seja, ela varia de acordo com o leitor contemporâneo e sua experiência, os objetivos da leitura, a corrente estética do autor, o momento histórico e geográfico em que foi escrita a obra, dentre inúmeras outras variáveis. Portanto, não temos a intenção de circunscrever uma forma de leitura, mas apontar caminhos possíveis que permitam fruir a obra de arte.

Nosso interesse recai sobre o estudo do teatro barroco, dito "antigo", ou seja, que segue os padrões e preceptivas anteriores aos movimentos iluminista e romântico. ${ }^{2}$ Trata-se de uma lógica bastante diversa da atual, no entanto interessantíssima do ponto de vista da relação entre texto e cena, pois a escrita deste período mantinha, ainda, forte ligação com o palco. Parafraseando Williams (2010), a dramaturgia contemporânea desenvolveu uma tendência a se afastar do raciocínio cênico, tornando-se, assim enfadonha e monótona cenicamente, ou ainda como diz Ruiz Ramón (1978, p. 17):

Cuando, además, se trata de leer textos clásicos, la distancia entre el tiempo histórico de autor y público primero del texto y el tiempo histórico del lector contemporáneo aumenta los riesgos que toda lectura de por sí comporta.

Uma das grandes questões relativas à contextualização histórica que se levanta quando do contato com textos dramáticos antigos são os anacronismos. Metaforicamente, podemos dizer que a época barroca está separada do leitor atual por uma muralha chamada "século XIX". Os modos de pensar a arte desenvolvidos pelos movimentos estético-culturais posteriores ao barroco e seus desdobramentos atuam ainda hoje no imaginário do leitor. ${ }^{3}$

\footnotetext{
2 Retomado pelo movimento romântico português, especialmente por Almeida Garret no Introito de Um auto de Gil Vicente (1996), Antônio José da Silva é tomado por mártir da Inquisição e uma possibilidade frustrada de nacionalização do teatro em Portugal. Visões anacrônicas de sua obra a consideram revolucionária, satírica ou crítica da sociedade e da corte de D. João $\mathrm{V}$, como o faz, por exemplo, Juliet Perkins (2004), na introdução da tradução para o inglês de O Labirinto de Creta. Os textos Há sátira em Antônio José da Silva? (2011) e Notas sobre os paradigmas para a composição das peças de Antônio fosé da Silva (2012) tratam da incongruência histórica das competências atribuídas ao dramaturgo pelos ecos da lógica romântica que ainda prevalecem no pensamento ocidental. Acerca desta questão, ainda fala Ruiz Ramón (1978, p. 19-20): "Un tercer riesgo - tal vez debiera llamarlo tentación - de la lectura actual de un texto del pasado, es aquella fácil y socorrida simplificación en que vienen a desembocar multitud de trabajos que a sí mismos se denominan 'sociológicos', y que consiste en establecer conexiones pretendidamente analógicas entre drama y sociedad, o dentro de la terminología que vengo usando, entre espacio dramático y espacio histórico".

3 Assim, como afirma Salvador Oliva (2000, p. 11): "allò que és possible en una època i en una estètica pot no ser possible en una altra època i en una altra estètica”.
} 
Pois, se não se pode desvencilhar destes modos de pensar dos quais se impregna o imaginário contemporâneo, há um limite para que eles não prejudiquem ou atribuam leituras controversas aos textos antigos. Especialmente para os textos dramáticos, é importante ressaltar as divergências históricas nos campos da representação e da linguagem empregados na escritura dos textos: "el discurs sempre està estretament unit al context, i nomes té sentit em aquest context i nomes es pot referir a elements d'aquest context" (ABELLAN, 2000, p. 39). ${ }^{4}$

Quando se trata do teatro barroco português, nitidamente periférico, deve-se cotejar os contextos históricos da produção artística de Espanha e Itália, cuja presença na obra de Antônio José da Silva é manifesta. Da Espanha, ainda reverberava em Portugal o teatro do Siglo de Oro, cuja preceptiva tragicômica é a base da construção dramatúrgica judeína. Da Itália, o gênero novo, a ópera, que atraía a atenção da corte lusitana, é refletida derrisoriamente nos textos populares representados no Teatro do Bairro Alto. Do próprio Portugal, a cultura popular, tradições, ditados, jogos e folguedos são trazidos à cena para entreter e agradar ao público. ${ }^{5}$

A tragicomédia espanhola fornece ao teatro barroco ibérico sua dicotomia estrutural entre elevado e rebaixado, trágico e cômico, principal e secundário, $g a-$ lán e gracioso. Esta variação, embora já utilizada por diferentes dramaturgos ao longo dos séculos, é sistematizada por Lope de Vega no início do século XVII e repetida à exaustão até a época de Antônio José em ambos os países. A caracterização tragicômica se percebe quando da leitura do texto, mas se concretiza definitivamente em suas diferenças na representação - ou imaginação da representação, como já tratado anteriormente. Sobre esta questão, por ser intrínseca à construção das personagens, discorreremos em seguida.

Resta, entretanto, lembrar que a preceptiva espanhola leva em conta o gosto do público e que, portanto, qualquer tentativa de sistematização muito hermética dos modelos cotejados tende a ser falha em algum aspecto. Se à primeira vista esta afirmação pode parecer dilatadora das fronteiras do gênero, ela é, ao contrário, muito limitante, pois o gosto do público anseia por "mais do mesmo". As variações tragicômicas espanholas giram em torno da honra, enquanto que as portuguesas tratam do amor, como bem afirma Montes (1992). Evidentemente, no imensurável âmbito do barroco ibérico, muitos textos dramáticos podem escapar a este escopo - o que, ainda assim, não anula a condição generalizante do gosto popular.

4 Tradução nossa: "o discurso sempre está estreitamente ligado ao contexto, os só faz sentido neste contexto e só pode se referir a elementos deste contexto".

5 "Quiero con esto señalar - y volveré a ello - algo que me parece obvio, pero que la crítica del teatro del Siglo de Oro, a lo menos parte de ella, suele olvidar: entre el mundo del drama de [Antonio] Buero [Vallejo, 1916-20oo,] y nuestro propio mundo, que es también el de Buero, establecemos casi automáticamente una continuidad analógica, un denso tejido de asociaciones, continuidad que olvidamos, en cambio, establecer entre el mundo del drama de Calderón, o de cualquier otro drama clásico, y el mundo histórico del espectador del siglo XVII. O, al menos, sospechar que pudo haber existido ese mismo denso tejido de asociaciones, cuya trama no es, naturalmente, fácil de descubrir" (Ruiz RAMón, 1987, p. 29-30). 
Antônio José da Silva, autor de um teatro comercial, sem a condição pejorativa do termo, "cedeu a si mesmo e ao riso das plateias" (Assis, 1942, p. 304).

No que concerne à presença italiana na dramaturgia judeína, ela está na paródia da ópera - ou uma versão lusitana da ópera bufa, que já figurava nos salões da corte portuguesa da época, mas que era demasiado custosa para os bolsos plebeus. A novidade, entretanto, atrai o público lisboeta setecentista ao Teatro do Bairro Alto, para ver as "óperas joco-sérias" de Antônio José da Silva.

A estrutura musical das peças de Antônio José se assemelha à de outros gêneros que se desenvolviam por toda a Europa à época e atendia ao gosto do público por ser cantada em língua-pátria - diferentemente da ópera italiana, mas ainda subsidiária desta. Só algumas partes das peças são cantadas e, embora a música se mostre "perfeitamente à vontade no estilo operístico italiano" (BRITO, 1989, p. 101), os trechos cantados podiam também ser entoados como "modinhas e outras pequenas peças que toda a gente trazia no ouvido" (Branco, 1959, p. 112).

Nas peças do Judeu, tais trechos são mais do que simplesmente números de entretenimento porque fazem parte da ação dramática. As personagens agem enquanto cantam, mudando de um estado a outro durante a execução da música, ou fazendo uma exposição de seus sentimentos ou de seus planos. De uma forma ou de outra, as árias são importantes para o entendimento da ação dramática pelo público, como se viu nas análises empreendidas.

Além da referência direta à inovação operística italiana, a cena de Antônio José da Silva ainda carrega a ascendência indireta da commedia dell'Arte, que chega ao seu teatro através da preceptiva tragicômica espanhola. Já apontamos uma possível origem do gracioso através da carnavalização dos bufões e rústicos medievais, relidos sob a óptica da commedia:

Pero junto a la repentización verbal es evidente que la comedia nueva española, otra vez por influencia de la commedia italiana, diseña con frecuencia figuras o caracteres que imponen su actuación más por el gesto que por la palabra, hábito que arraiga en la generación de los actores-autores y que fue cualidad técnica preponderante cuando las compañías de cómicos all'improvviso comenzaron a desplazarse por Europa recitando en un idioma que los espectadores no italianos desconocían. Sea como fuere, lo cierto es que esta técnica accional y declamativa (que Huarte de San Juan definirá como 'soltura en el decir o invención que facilite el encaje de las sentencias') se vincula en el Siglo de Oro a la esfera del gracioso. (Rodríguez CuAdros, 1998, p. 104-105)

Num trabalho desenvolvido no âmbito dos Estudos Literários, a consideração de um gênero primordialmente gestual pode supor uma leitura despropositada e até contraditória. Entretanto, 
como ha señalado Eugenio Barba a propósito de su registro enérgico, el registro del actor de la commedia dell'arte no comportaba únicamente una técnica corporal sino literaria, entendiendo por ésta la energía retórica y declamatoria, la deformación artificiosa del léxico mediante todo tipo de procedimientos cacofónicos o de paranomasia sobre la emisión de la voz, sobre su pronunciación y los acentos (RodríGuEZ CuADRos, 1998, p. 97).

Assim, todas as atribuições cômicas rebaixadas, tomadas por menos dignas de nota por parte da fortuna crítica judeína, são aqui novamente justificadas por um paradigma de elaboração que parte de outros pressupostos, que não a cultura erudita europeia. Dizemos novamente porque, na análise dedicada às personagens baixas (graciosos e criadas), pudemos justificar cada inserção burlesca em relação à necessidade do gênero. Entretanto, a linguagem gestual não está presente apenas na composição da figura do gracioso - na qual, contudo, ela se destaca. Toda a gama de personagens de que Antônio José lança mão deve ser tida nesta chave de leitura. Como ainda afirma Rodríguez Cuadros (1998, p. 381):

Cada papel o al menos algunos de ellos, marcados por la tradición, supondrían en realidad un encadenamiento o repertorio de gestos codificados. Gesto que abarcaría toda una serie de elementos, desde las composiciones de tipos fijos al mero e ingenuo disfraz o las situaciones tópicas (escenas de tiernos equívocos entre los enamorados, de anfibológicos chascarrillos entre amo y criado, etc.). Gesto que cabe recuperar y deducir - pues no tenemos territorio documental que nos afirme en la total certidumbre.

Desta dedução cabe o entendimento das convenções barrocas, através de uma leitura que as considere na criação das imagens. Todas as questões sobre escrita e interpretação do texto dramático recaem sobre o conceito de convenção, que, para o Prof. Luiz Fernando Ramos, está sempre sujeito e limitado às tradições de determinada época:

Uma convenção, no sentido mais simples, é só um método, uma peça técnica da maquinaria, que facilita o espetáculo. Mas os métodos mudam e as técnicas mudam, e enquanto, digamos, um coro de dançarinos, ou o manto de invisibilidade, ou um solilóquio cantado são conhecidos métodos dramáticos, eles não poderão ser satisfatoriamente utilizados a não ser que, à época do espetáculo, sejam mais que métodos, a não ser que eles sejam convenções. Dramaturgos, atores e público devem ser capazes de concordar que o método particular a ser empregado é aceitável; e, dependendo do caso, uma parte importante desse acordo deve usualmente preceder o espetáculo, de modo que o que está por ser feito seja aceito sem fricções danosas (Williams, 2010, p. 9).

Quando falamos de convenções do texto dramático, primeiramente estamos tratando da forma através da qual a trama se desenrola perante o público, ou seja, 
os elementos formais, as ferramentas de escrita do dramaturgo, exemplificadas no excerto acima. Todavia, ainda há, num texto dramático, a cena. Se pontuamos regularmente este aspecto, é porque ele esteve e deve estar a todo momento em nosso campo de análise e leitura.

Na leitura das convenções barrocas de escrita dramática devemos atentar também para os aspectos da representação - os quais, entretanto, são supostos, e não historicamente documentados. Podemos falar, portanto, de uma leitura realizada tecnicamente, em oposição a uma leitura instintiva, pois considera os aspectos formais, estruturais, históricos, de representação, e outros que corroborem a construção da representação mental do texto lido:

tot depèn de la convenció utilitzada; no hi ha cap forma artística o dramatúrgica que, per naturalesa, estigui incapacitada per fer el que es proposa, dintre dels limits establerts per la convenció adoptada (SALA, 2000, p. 30$)^{6}$

Neste sentido, no que concerne aos aspectos representacionais do texto dramático, ou seja, às questões do gesto e movimentação cênica depreendidas das falas e das situações de tensão entre as personagens, vejamos o que diz Rodríguez $\mathrm{Cu}-$ adros (1998, p. 381):

Pero ese potencial gestual se produce, en todo caso, en el ámbito de un universo espectacular convencional que puede coincidir o no con una relación mecánica imagen/realidad. Quiero decir que debe tenerse en cuenta la referencia al contexto cultural.

Central na discussão é a questão do anacronismo na leitura dos textos antigos. Os principais pontos de anacronismo presentes na leitura do teatro barroco que gostaríamos de ressaltar dizem respeito justamente a mecanismos produtores de imagens mentais da representação das peças: a atuação e a linguagem empregadas na representação e na escrita das peças, ambos aspectos relacionados à construção das personagens.

Tratando-se do contexto teatral barroco, faz-se necessário entender melhor, portanto, a caracterização das personagens e sua relação de vontades e oposições que movem a trama. Tais aspectos, ligados diretamente à construção da personagem, serão tratados a seguir. Por ora, basta lembrar que, se dissociamos a leitura híbrida, a contextualização histórica e a caracterização das personagens para a análise de textos dramáticos, o fazemos com a finalidade única de organização do pensamento. No ato de ler em si, todos estes aspectos e outros que sejam convocados

\footnotetext{
6 Tradução nossa: "tudo depende da convenção utilizada; nenhuma forma artística ou dramatúrgica, por natureza, está incapacitada de fazer o que se propõe, dentro dos limites estabelecidos pela convenção adotada”.
} 
a cada peça se completam e dialogam entre si, ampliando o próprio significado e a complexidade do texto.

Retomando nossa primeira questão, acerca da leitura contemporânea de textos antigos, evocamos a figura do pensador teatral Henri Gouhier (1943):

Atualização [...] não se trata de executar, mas de ressuscitar. [...] Representar é tornar presente através de presenças.

A atualização ${ }^{7}$ de que trata Gouhier, especialmente quando falamos da leitura de textos antigos, não versa o anacronismo de uma obra. Esta atualização pode ser entendida como uma rede de referências e paralelismos elaborados a partir do pensamento contemporâneo (do leitor), para completar o entendimento do pensamento passado (presente na obra). As relações estabelecidas aparentemente não são binárias - este do passado é igual àquele do presente -, mas uma teia de complexas analogias, cuja finalidade é o entendimento da universalidade daquele texto.

Análogo à ideia de atualização de Gouhier é o que Ruiz Ramón (1997) chama de adaptação. Tanto na encenação quanto na leitura, a adaptação de que trata o autor se refere à interação estabelecida entre el mundo de ayer e el mundo de hoy, ou seja, o que o texto dramático clássico comunica ao leitor ou espectador contemporâneo. Afinal de contas, autores como Shakespeare, Calderón de La Barca, Corneille e Antônio José; são homens que enxergam a realidade circundante e com ela dialogam, mesmo que não de forma crítica - na acepção atual da palavra. Sendo, portanto, testemunhas lúcidas do seu tempo e espaço, podemos ler seus textos a partir da chave oferecida pelo teórico espanhol:

Aunque nunca apliquemos el vocablo "adaptar" o "adaptación" al acto de lectura del texto clásico, también la complejísima operación de leer, en este caso, un texto teatral clásico implica, en el fondo, la operación de "adaptar" el sistema - y no sólo el lingüístico, sino el de la totalidad de los signos - del texto leído al sistema del lector. Incluso el lector mejor pertrechado de erudición histórica, capaz de situar con rigor el texto en su contexto original, difícilmente podrá leerlo en el proprio contexto del texto, pues dicho contexto no existe en sí más que como producto de interpretación, es decir, como objeto intelectual elaborado. Y aun en el caso ideal de una absoluta inmersión en el contexto y de una total identificación con él, seguiría en pie el problema del sentido del texto, el cual nunca deriva sólo de su contexto (Ruiz RAmón, 1984, p. 9-10).

7 Tal pensamento também pode ser encontrado na teoria bergsoniana, como apresenta Baltazar (2014, p. 98): "O corpo executa ações. As ações são atualizações na matéria de toda a virtualidade do espírito. Sem o corpo, a virtualidade não se atualiza. A ação é o cume do presente e está, através do corpo, impregnada de sensações e pensamentos". 
Estamos longe de um consenso ou de um caminho único de leitura do texto dramático antigo e, embora tal afirmação seja um clichê, é importante ressaltar que cada texto requer uma chave de leitura distinta. Mas algumas diretrizes são identificadas nos autores cotejados neste trabalho, especialmente no que tange à participação ativa do leitor no processo de interpretação dos textos. Assim, uma vez que há, mesmo sub-repticiamente, a intenção da escrita para cena coetânea, afirma Ruiz Ramón (1997, p. 17) que:

Problemas que son determinantes o condicionantes, en el tiempo de la creación, tanto de su concepción como de su escritura por el dramaturgo [...], ya que éste al concebir un espectáculo no lo hace en un vacío de tiempo, sino en un tiempo histórico concreto - el suyo y el de sus espectadores donde dominan determinadas prácticas de puesta en espectáculo en relación de concordancia (o discordancia) con su propia concepción; relación que, al mismo tiempo, condiciona su escritura del texto, sujeto a su vez a una práctica de puesta en espectáculo que puede reducirlo o enriquecerlo como texto teatral y, consecuentemente, producir, por el montaje escénico, condiciones de recepción por parte del público, impuestas a éste en y por la escena, que imposibiliten o desvíen la lectura del texto teatral como conciliación dialéctica del "texto-teatro" y el "texto-espectáculo".

Assim, para ler textos antigos na contemporaneidade, tendo em conta o conhecimento construído acerca do assunto, se faz relevante a compreensão e a transposição do pensamento do leitor para o contexto no qual a obra foi composta. Paradoxalmente, este mesmo leitor deve ressignificar o texto lido em seu próprio contexto de recepção, pois é a partir deste que poderá interpretar e fruir a obra artística.

Uma vez mais, portanto, nos encontramos num vértice em que não existem respostas prontas ou métodos bem aparados a seguir, mas diretrizes, sistemas de organização do imaginário que podem ser mais ou menos fixados pelo leitor em cada leitura. O mais importante, entretanto, a pedra de toque de nossa discussão e de nossa análise é a possibilidade de o leitor entrar em contato com o texto dramático em toda a sua potencialidade artístico-criativa.

\section{Referências}

Abellan, Joan. El text dramàtic. In: Sala, Jordi (ed.). Deu lliçons sobre teatre: text i representació. Girona: Servei de Publicacions de la Universitat de Girona, 2000. p. $35-43$.

Assis, Machado de. Antônio José (1879). Crítica Teatral. Rio de Janeiro: W. M. Jackson Inc. 1942.

Baltazar, Márcia Cristina. Relações entre o agir, o sentir e o pensar no ato criativo: uma análise bergsoniana. Sala Preta, v. 14, p. 95-107, 2014. Disponível em 
http://www.revistas.usp.br/salapreta/article/viewFile/84481/91864. Acesso em 02 jan. 2017.

Branco, João de Freitas. O teatro de "O Judeu". História da música portuguesa. Lisboa: Europa-América. 1959.

Brito, Manuel Carlos. Estudos de História da Música em Portugal. Lisboa: Editorial Estampa. 1989.

Garrett, Almeida. Um auto de Gil Vicente. Lisboa: Replicação. 1996.

Gontijo Rosa, Carlos. Há sátira em Antônio José da Silva? Anuário de Literatura, v. 16, n. 2, p. 101-113, 2011.

Gontijo Rosa, Carlos. Notas sobre os paradigmas para a composição das peças de Antônio José da Silva. Webmosaica - Revista do Instituto Cultural fudaico Marc Chagall, v. 4, n. 2, p. 39-48, jul.-dez. 2012.

Gounier, Henri. A essência do teatro. L'Essence du Théâtre. Tradução de Roberto Mallet. Paris: Librarie Plon. 1943. p. 1-7. Disponível em www.grupotempo.com.br/tex_gouhier.html. Acesso em: 15 abr. 2012.

Kopelman, Isa Etel. Questões de texto e cena. Pitágoras, 50o, v. 1, p. 62-71, out. 2011.

MonTes, José Ares. Bodas y divorcio del teatro hispano-portugués. In: Congresso Luso-Espanhol de Teatro, I. Dramaturgia e Espetáculo: Actas. Coimbra, 23 a 26 de setembro de 1987. Coimbra: Livraria Minerva. 1992.

Oliva, Salvador. Literatura dramàtica i teatre. In: SAlA, Jordi (ed.). Deu lliçons sobre teatre: text i representació. Girona: Servei de Publicacions de la Universitat de Girona, p. 11-20. 2000.

Pallottini, Renata. Dramaturgia: a construção da personagem (1989). São Paulo: Perspectiva. 2015.

Rodríguez CuAdros, Evangelina. La técnica del actor español en el Barroco: hipótesis y documentos. Fuenlabrada: Castalia. 1998.

Ruiz Ramón, Francisco. Calderón y la tragedia. Madrid: Alhambra. 1984.

Ruiz Ramon, Francisco. Estudios de teatro español clásico y contemporáneo. Madrid: Fundación Juan March. 1978.

Ruiz Ramón, Francisco. Paradigmas del teatro clásico español. Madrid: Cátedra. 1997.

SAla, Jordi. El teatre com a discurs narratiu de ficció. In: SALA, Jordi (ed.). Deu lliçons sobre teatre: text i representació. Girona: Servei de Publicacions de la Universitat de Girona. 2000. p. 21-34. 
Silva, Antônio José da. A critical study and translation of António fosé da Silva's Cretan Labyrinth: a puppet opera. Tradução e estudo crítico de Juliet Perkins. Lewiston: Edwin Mellen. 2004.

Williams, Raymond. Drama em cena. Tradução de Rogério Bettoni. São Paulo: Cosac Naify. 2010.

Recebido em 24 de junho de 2018.

Aprovado em 21 de fevereiro de 2019.

\section{Resumo/Abstract/Resumen}

Escrito para a cena barroca: a contextualização histórica na leitura contemporânea de textos dramáticos antigos

\section{Carlos Gontijo Rosa}

O leitor, a partir do seu próprio imaginário, constrói as cenas que lê num texto dramático. Assim, num contato mais imediato com o texto, o leitor organiza as ações da peça a partir de seu próprio referencial imagético. Em textos contemporâneos, especialmente aqueles que dialogam diretamente com as novas formas da cena, com sua hibridização entre as diferentes formas artísticas, é evocada a necessidade de algum conhecimento desta cena, pois o texto dramático é escrito com vistas a ser posto em cena em sua contemporaneidade. O mesmo acontece com o texto dramático antigo, pois também ele dialoga com as formas de representação vigentes. Tal relação é especialmente importante de ser levada em conta quando se está em contato com textos definitivamente escritos com o objetivo de serem representados. A condição de serem escritos para a cena, por sua vez, não exime o autor de tais textos de um compromisso literário, mas agrega ambos sob sua égide. Quando nós, leitores do século XXI, nos deparamos com textos dramáticos em geral, apresentamos uma tendência a lê-los primeiramente a partir do nosso imaginário do que é teatro hoje. Sabemos que nossa imaginação está impregnada do nosso próprio tempo-espaço e apresenta as mais diversas influências, inconscientemente. Entretanto, no que tange ao tratamento de textos muito antigos ou baseados em preceptivas muito distantes das conhecidas pelo leitor, esta relação assimétrica pode prejudicar a apreciação da obra. Uma leitura empenhada de textos, dramáticos ou não, deve considerar seu contexto de produção, seja históricocultural, seja cênico-literário. Esta condição da leitura permitirá que o leitor compreenda os meandros do jogo cênico proposto pelo dramaturgo e complementará o caráter imaginativo do ato de ler. Para efeitos de análise, tomaremos por base as peças mitológicas do dramaturgo português setecentista Antônio José da Silva como objeto para o desenvolvimento da discussão que segue.

Palavras-chave: leitura, teatro, texto, cena. 


\section{Written for the Baroque Stage: Historical Contextualization in the Con-} temporary Reading of Olden Dramatic Texts

\section{Carlos Gontijo Rosa}

The reader uses their own imaginary to construct the scenes that they read in a dramatic text. Thus, in immediate contact with the material, the reader organises the action based on their own imagisitic frame of reference. In contemporary texts - especially those which directly dialogue with the new forms of the scene, with their hybridization between the differing artistic forms - the requirement of some knowledge about this scene comes to the fore; the dramatic text is written with the intention of being staged in its contemporaneity. The same happens with olden dramatic texts as they also dialogue with the forms of representation at the time of their writing. It is especially important to take this relationship into account when dealing with texts which were written with the concrete objective of being staged. The condition of being written for the stage does not, in turn, exempt the author of these texts from a literary commitment; rather it brings both under the same aegis. When we, as 21st century readers, come across dramatic texts in general, we tend to read them primarily based on our notions of what theatre is today. We know that our imagination is impregnated with our own time-space and it subconsciously presents the most diverse influences. However, with regard to the treatment of texts that are very old or based on precepts far removed from those known by the reader, this asymmetrical relationship may impair the appreciation of the work. A committed reading of texts, dramatic or not, must consider the context of their production, be it historical-cultural or scenic-literary. This condition of reading will allow the reader to understand the intricacies of the scenic play proposed by the playwright and will complement the imaginative aspect of the act of reading. For purposes of analysis, we will take as a basis the mythological works of the eighteenth-century Portuguese playwright Antônio José da Silva as a subject for the development of the discussion that follows.

Keywords: reading, theatre, text, scene.

\section{Escrito para la escena barroca: la contextualización histórica en la lectura contemporánea de textos dramáticos antiguos}

\section{Carlos Gontijo Rosa}

El lector, a partir de su propio imaginario, construye las escenas que lee en un texto dramático. Así, en un contacto más inmediato con el texto, el lector organiza las acciones de la pieza desde su propio referencial imagético. En textos contemporáneos, especialmente en aquellos que dialogan directamente con las nuevas formas de la escena y que hibridizan diferentes formas artísticas, es evocada la necesidad de algún conocimiento sobre la escena, toda vez que el texto dramático 
ha sido escrito con vistas a la representación en su contemporaneidad. Ocurre lo mismo con el texto antiguo, pues también éste dialoga con las formas de representación vigentes en su tiempo. Tal relación es especialmente importante cuando se leen textos definitivamente escritos objetivando su representación. La condición de que sean escritos para la escena, a su vez, no evita al autor un compromiso literario, pero une a ambos bajo la misma égida. Cuando nosotros, lectores del siglo veintiuno, nos encontramos con textos dramáticos en general, experimentamos cierta tendencia a leerlos en primer lugar a través de nuestro imaginario, del nuestra idea sobre el teatro hoy. Sabemos además que nuestra imaginación está llena de nuestro propio tiempo-espacio y presenta las más variadas influencias, de forma inconsciente. No obstante, en lo que se refiere al tratamiento de textos muy antiguos o basados en preceptivas muy lejanas de las que el lector conoce, esta relación asimétrica puede perjudicar la apreciación de la obra. Una lectura comprometida de textos, dramáticos o no, debe considerar su contexto de producción histórico-cultural o escénico-literario. Esta condición de lectura permitirá que el lector comprenda los meandros del juego escénico propuesto por el dramaturgo y completará el carácter imaginativo del acto de lectura. En este análisis, tomaremos como punto de partida para la discusión las piezas mitológicas del dramaturgo portugués del siglo XVIII António José da Silva.

Palabras clave: lectura, teatro, texto, escena. 